University of Montana

ScholarWorks at University of Montana

Integrative Physiology and Athletic Training

Faculty Publications

Integrative Physiology and Athletic Training

$11-2009$

\title{
Successive Bouts of Cycling Stimulates Genes Associated with Mitochondrial Biogenesis
}

Charles Dumke

University of Montana - Missoula, charles.dumke@umontana.edu

J. Mark Davis

University of South Carolina - Columbia

E. Angela Murphy

University of South Carolina - Columbia

David C. Nieman

Appalachian State University

Martin D. Carmichael

University of South Carolina - Columbia

See next page for additional authors

Follow this and additional works at: https://scholarworks.umt.edu/hhp_pubs

Part of the Medicine and Health Sciences Commons

Let us know how access to this document benefits you.

\section{Recommended Citation}

Dumke, Charles; Davis, J. Mark; Murphy, E. Angela; Nieman, David C.; Carmichael, Martin D.; Quindry, John C.; Triplett, N. Travis; Utter, Alan C.; Gross Gowin, Sarah J.; Henson, Dru; McAnulty, Steven R.; and McAnulty, Lisa S., "Successive Bouts of Cycling Stimulates Genes Associated with Mitochondrial Biogenesis" (2009). Integrative Physiology and Athletic Training Faculty Publications. 13.

https://scholarworks.umt.edu/hhp_pubs/13

This Article is brought to you for free and open access by the Integrative Physiology and Athletic Training at ScholarWorks at University of Montana. It has been accepted for inclusion in Integrative Physiology and Athletic Training Faculty Publications by an authorized administrator of ScholarWorks at University of Montana. For more information, please contact scholarworks@mso.umt.edu. 


\section{Authors}

Charles Dumke, J. Mark Davis, E. Angela Murphy, David C. Nieman, Martin D. Carmichael, John C. Quindry, N. Travis Triplett, Alan C. Utter, Sarah J. Gross Gowin, Dru Henson, Steven R. McAnulty, and Lisa S. McAnulty 


\title{
Successive bouts of cycling stimulates genes associated with mitochondrial biogenesis
}

\author{
Charles L. Dumke · J. Mark Davis · E. Angela Murphy • David C. Nieman • \\ Martin D. Carmichael · John C. Quindry · N. Travis Triplett • Alan C. Utter • \\ Sarah J. Gross Gowin · Dru A. Henson · Steven R. McAnulty · Lisa S. McAnulty
}

Accepted: 21 July 2009 / Published online: 6 August 2009

(C) Springer-Verlag 2009

\begin{abstract}
Exercise increases mRNA for genes involved in mitochondrial biogenesis and oxidative enzyme capacity. However, little is known about how these genes respond to consecutive bouts of prolonged exercise. We examined the effects of $3 \mathrm{~h}$ of intensive cycling performed on three consecutive days on the mRNA associated with mitochondrial biogenesis in trained human subjects. Forty trained cyclists were tested for $\mathrm{VO}_{2 \max }\left(54.7 \pm 1.1 \mathrm{ml} \mathrm{kg}{ }^{-1} \mathrm{~min}^{-1}\right)$. The subjects cycled at $57 \%$ watts $_{\max }$ for $3 \mathrm{~h}$ using their own bicycles on CompuTrainer ${ }^{\mathrm{TM}}$ Pro Model trainers (RacerMate, Seattle, WA) on three consecutive days. Muscle biopsies were obtained from the vastus lateralis pre- and post-exercise on days one and three. Muscle samples were analyzed for mRNA content of peroxisome proliferator receptor gamma coactivator-1 alpha (PGC- $1 \alpha$ ), sirtuin 1 (Sirt-1), cytochrome $c$, and citrate synthase. Data were analyzed using a 2 (time) $\times 2$ (day) repeated measures ANOVA. Of the mRNA analyzed, the following increased
\end{abstract}

\section{L. Dumke $(\bowtie)$}

Department of Health and Human Performance,

University of Montana, 103 McGill Hall,

32 Campus Drive, Missoula, MT 59812, USA

e-mail: charles.dumke@mso.umt.edu

J. Mark Davis · E. Angela Murphy · M. D. Carmichael

Division of Applied Physiology,

Arnold School of Public Health,

University of South Carolina, Columbia, SC, USA

D. C. Nieman · J. C. Quindry · N. Travis Triplett - A. C. Utter ·

S. J. Gross Gowin · D. A. Henson · S. R. McAnulty

Department of HLES, Appalachian State University,

Boone, NC, USA

L. S. McAnulty

Department of Family and Consumer Sciences,

Appalachian State University, Boone, NC, USA from pre to post $3 \mathrm{~h}$ rides: cytochrome $c(P=0.006)$, citrate synthase $(P=0.03)$, PGC- $1 \alpha \quad(P<0.001)$, and Sirt-1 $(P=0.005)$. The following mRNA showed significant effects from days one to three: cytochrome $c(P<0.001)$ and citrate synthase $(P=0.01)$. These data show that exhaustive cycling performed on three consecutive days resulted in both acute and chronic stimuli for mRNA associated with mitochondrial biogenesis in already trained subjects. This is the first study to illustrate an increase in sirtuin-1 mRNA with acute and chronic exercise. These data contribute to the understanding of mRNA expression during both acute and successive bouts of prolonged exercise.

Keywords Mitochondrial density - Oxidative enzymes . Cycling economy $\cdot$ Endurance exercise

\section{Introduction}

The elevation in mitochondrial capacity in skeletal muscle following endurance exercise training was first described by Holloszy (1967). These peripheral adaptations following exercise are considered some of the more important responses which allow enhanced endurance performance and resistance to fatigue. Since then, scientists have been trying to better understand the stimuli that result in an upregulation of mitochondrial capacity following exercise training. Recent advances in molecular biology have improved our understanding of underlying stimuli and pathways for this exercise adaptation.

Intracellular messengers during muscle contraction (calcium, ADP, AMP, cAMP, Pi) induce upregulation of several upstream proteins such as AMP-activated protein kinase (AMPK) and peroxisome proliferator receptor 
gamma coactivator-1 alpha (PGC-1 $\alpha$ ) (Civitarese et al. 2007, 2005; Freyssenet 2007). PGC- $1 \alpha$ lies upstream of the nuclear respiratory factors (NRF) 1 and 2 and mitochondrial transcription factor A (TFAM) which regulates both the genomic and mitochondrial gene expression involved in mitochondrial adaptation (Civitarese et al. 2007; Hood et al. 2006; Wright et al. 2007). PGC- $1 \alpha$ potency seems to be further controlled in part by p38 mitogen activated protein kinase (MAPK) (Ikeda et al. 2008; Wright et al. 2007) and sirtuin 1 (Sirt-1). Sirt-1 is a NAD ${ }^{+}$sensing protein that deacetylates PGC- $1 \alpha$ thus improving its ability to activate downstream transcription of genes involved in oxidative metabolism (Nemoto et al. 2005). The role of Sirt-1 during exercise, particularly in humans, has yet to be convincingly described. Sirt-1 expression decreases with aging, and this is attenuated by exercise in heart, adipose tissue and skeletal muscle in murine models (Canto et al. 2009; Ferrara et al. 2008; Suwa et al. 2008). Recent data indicates that AMPK activation enhances Sirt-1 activity and its targets, such as PGC- $1 \alpha$ (Canto et al. 2009). Downstream targets of PGC- $1 \alpha$ include both genomic and mitochondrial genes involved in oxidative metabolism such as cytochrome $c$ and citrate synthase (Hood 2001; Wright et al. 2007).

Acute exercise increases transcription of genes, and upregulation of protein content involved in mitochondrial biogenesis. An increase in PGC- $1 \alpha$ mRNA (Goto et al. 2000) and protein (Baar et al. 2002; Wright et al. 2007) has been demonstrated following both an acute bout and several days of swimming in rats. In humans, 6 weeks of endurance training resulted in increases in PGC- $1 \alpha$ mRNA and protein in all muscle fiber types but most dramatically in type IIa (Russell et al. 2003). In a novel single leg extensor exercise, it was found that both acute and chronic exercise result in a transient increase in PGC- $1 \alpha$ mRNA (Pilegaard et al. 2003). Miura et al. (2007) showed that PGC- $1 \alpha$ mRNA increased following treadmill running in mice and that this increase was attenuated by a $\beta 2$ adrenergic receptor antagonist. Conversely, physical inactivity results in downregulation of PGC- $1 \alpha$ mRNA (Timmons et al. 2006). Despite this evidence, there remains no data on the effect of consecutive bouts of exercise on mitochondrial biogenesis markers in humans.

Previous studies have examined the effects of a single bout of exercise on mitochondrial biogenesis, however, to our knowledge there have been no studies that have examined the effects of consecutive days of exercise on markers of mitochondrial biogenesis in trained subjects. Therefore, the purpose of this investigation is to determine how genes associated with mitochondrial biogenesis respond to several consecutive bouts of intensive exercise in trained subjects. We hypothesized that despite being trained, the exercise protocol would be sufficiently rigorous to cause an increase in the mRNA of upstream markers of mitochon- drial biogenesis (PGC- $1 \alpha$ and Sirt-1) and downstream targets (cytochrome $c$ and citrate synthase).

\section{Materials and methods}

\section{Subjects}

Forty trained male cyclists were recruited as experimental subjects through local and collegiate cycling clubs. Written informed consent was obtained from each subject. These experimental procedures were approved by the institutional review board of Appalachian State University (ASU).

\section{Research design}

Subjects reported to the ASU Human Performance Lab for orientation and measurement of body composition and cardiorespiratory fitness. Body composition analysis was performed by hydrostatic weighing in a custom built, stainless steel tank with three load cells interfaced to a computer (Exertech Fitness Equipment, Dresbach, MN). Body fat was subsequently calculated from the Siri equation using predicted residual volume (Siri 1961). $\mathrm{VO}_{2 \max }$ and maximum power were determined using a graded maximal protocol (25 watt increase every two minutes starting at 150 watts) with the subjects riding their own bicycles on CompuTrainer ${ }^{\mathrm{TM}}$ Pro Model 8001 trainers (RacerMate, Seattle, WA). Oxygen uptake and metabolic parameters were measured using the MedGraphics CPX metabolic system (MedGraphics Corporation, St. Paul, MN). Heart rate was measured using a chest heart rate monitor (Polar Electro Inc., Woodbury, NY). Maximum workload was extrapolated from the amount of time completed during the last stage. Basic demographic and training data were obtained through a questionnaire.

Subjects avoided the use of large-dose vitamin/mineral supplements (above $100 \%$ of recommended dietary allowances), medications, nutritional supplements, ergogenic aids, and herbs during the testing period. During orientation, a dietitian instructed the subjects to follow a diet moderate in carbohydrate during the 3 days prior to and during the 3-day test sessions and record intake in a food record. The food records were analyzed using a computerized dietary assessment program (Food Processor, ESHA Research, Salem, OR).

Subjects came to the lab for three consecutive days and cycled for $3 \mathrm{~h}$ at $\sim 57 \%$ Watts $_{\max }$. Subjects reported to the lab at 2:00 pm not having ingested energy in any form after 12:30 pm. Muscle biopsies were collected from the vastus lateralis 15 min pre-ride and immediately post-ride on the first and third day. Subjects ingested only water $15-30 \mathrm{~min}$ pre-exercise $(0.5-1.0 \mathrm{~L})$ and during the 3 -h cycling bouts 
(0.5-1.0 $\left.\mathrm{L} \mathrm{h}^{-1}\right)$. No other beverages or food were ingested during the test sessions.

During the exercise trials, the subjects' own bicycles were fitted to laboratory CompuTrainer ${ }^{\mathrm{TM}}$ Pro Model 8001 trainers (RacerMate, Seattle, WA) with the exercise load set at $57 \%$ maximal watts following the manufacturerrecommended calibration. Body weight was recorded preand post-exercise trials. Metabolic measurements were made every 30 min of cycling using the MedGraphics CPX metabolic system (MedGraphics Corporation, St. Paul, MN). Workload, average cadence, and overall rating of perceived exertion (RPE) (Borg 1982) were also collected every $30 \mathrm{~min}$. Subjects were encouraged to maintain a self selected cadence. In rare instances, subjects were unable to maintain consistent cadence, or if RPE rose to greater than 18 , then workload was decreased in order for the rider to complete the trial. Previous reports suggest that cadence can decrease by more than $20 \mathrm{rev} \mathrm{min}^{-1}$ with minimal $(<2 \%)$ effects on efficiency (Moseley et al. 2004). Workload was not adjusted within $10 \mathrm{~min}$ of metabolic measurements to ensure steady state during those measurements.

\section{Muscle biopsies}

Muscle biopsies were obtained from the vastus lateralis before and after the first and third test rides. The post-test biopsy was obtained $\sim 2 \mathrm{~cm}$ proximal from the pre-test biopsy site. For the third 3-h ride, samples were collected from the opposite leg, with leg order randomly determined. Local anesthesia (2\% xylocaine) was injected subcutaneously and intramuscularly. Following a small incision ( $\sim 0.5 \mathrm{~cm})$, a muscle biopsy sample $(\sim 100 \mathrm{mg})$ was obtained using the percutaneous needle biopsy procedure modified to include suction (Evans et al. 1982). Muscle was trimmed of connective tissue and fat and immediately frozen in liquid nitrogen. Samples were stored at $-80^{\circ} \mathrm{C}$ until subsequent analysis.

\section{Muscle glycogen analysis}

Muscle samples $(\sim 10 \mathrm{mg})$ were homogenized in $0.3 \mathrm{M}$ perchloric acid and glycogen digested by the amyloglucosidase method (Passonneau and Lauderdale 1974). The resulting glucose moieties were quantified spectrophotometrically (Genesys 5, Thermo Spectronic, Rochester, NY) in the presence of hexokinase and glucose-6-phosphate dehydrogenase.

\section{Muscle RNA isolation and cDNA synthesis}

Procedures for RNA isolation have been described previously (Nieman et al. 2005). Briefly, skeletal muscle tissue was homogenized under liquid nitrogen using a polytron, and total RNA was extracted using the guanidine thiocyanate method with TRIzol Reagent (Life Technologies, GibcoBRL). The extracted RNA ( $2.5 \mu \mathrm{l}$ of sample) was dissolved in diethylpyrocarbonate-treated water and quantified spectrophotometrically at 260-nm wavelength. RNA was reverse transcribed into cDNA in a $50 \mu \mathrm{l}$ reaction volume containing $19.25 \mu \mathrm{l}$ RNA $(1.5 \mu \mathrm{g})$ in RNase-free water, $5 \mu \mathrm{l} 10 \times \mathrm{RT}$ buffer, $11 \mu \mathrm{l} 25 \mathrm{mM} \mathrm{MgCl}_{2}, 10 \mu \mathrm{l}$ deoxyNTPs mixture, $2.5 \mu \mathrm{l}$ random hexamers, $1 \mu$ l RNase inhibitor, and $1.25 \mu \mathrm{l}$ multiscribe reverse transcriptase $(50 \mathrm{U} / \mu \mathrm{l})$. Reverse transcription was performed at $25^{\circ} \mathrm{C}$ for $10 \mathrm{~min}, 37^{\circ} \mathrm{C}$ for $60 \mathrm{~min}$, and $95^{\circ} \mathrm{C}$ for $5 \mathrm{~min}$, followed by quick chilling on ice and stored at $-20^{\circ} \mathrm{C}$ until subsequent amplification.

\section{Quantitative real-time PCR analysis}

Quantitative real-time polymerase chain reaction (qPCR) analysis was done as per manufacturer's instructions using TaqMan $^{\circledR}$ Gene Expression Assays (Applied Biosystems, Foster City, CA). DNA amplification was carried out in $12.5 \mu \mathrm{l}$ Taqman Universal PCR Master Mix (AmpliTaq Gold DNA Polymerase, Passive Reference 1, Buffer, dNTPs, AmpErase UNG), $1 \mu \mathrm{l}$ cDNA, $9 \mu$ l RNase-free water, and 1.25 $\mu 1$ 18S primer (VIC) (Endogenous Control (VIC ${ }^{\circledR} / \mathrm{MGB}$ Probe, catalog number 4352341E)) and $1.25 \mu \mathrm{l}$ primer (FAM) (Target Gene (catalog numbers: PGC-1 $\alpha$ : Hs00173304_m1, SIRT-1: Hs01009006_m1, cytochrome $c$ : Hs01588974_g1 and citrate synthase: Hs00830726_sH) in a final volume of $25 \mu \mathrm{l} /$ well. Human control RNA (calibrator RNA) was also used and served as a calibrator for each plate. Samples were loaded in a MicroAmp 96-well reaction plate in duplicate. Plates were run using ABI Sequence Detection System. After 2 min at $50^{\circ} \mathrm{C}$ and $10 \mathrm{~min}$ at $95^{\circ} \mathrm{C}$, plates were coamplified by 40 repeated cycles of which one cycle consisted of $15 \mathrm{~s}$ denaturing step at $95^{\circ} \mathrm{C}$ and $1 \mathrm{~min}$ annealing/extending step at $60^{\circ} \mathrm{C}$. Data was analyzed by ABI software using the CT, cycle threshold, which is the value calculated and based on the time (measured by PCR cycle number) at which the reporter fluorescent emission increases beyond a threshold level (based on the background fluorescence of the system), and it reflects the cycle number at which the cDNA amplification is first detected.

\section{Calculations for relative quantification}

Quantification of mRNA content for muscle cytochrome $c$, PGC- $1 \alpha$, citrate synthase, and sirt- 1 was calculated using the $\Delta \Delta \mathrm{CT}$ method as described by Livak and Schmittgen (2001). This method uses a single sample, the calibrator sample, for comparison of every unknown sample's mRNA. This method of analysis and quantification has 
been shown to give similar results as the standard curve method. Briefly, $\Delta \mathrm{CT}$ (CT(FAM) - CT(VIC)) was calculated for each sample and calibrator. $\Delta \Delta \mathrm{CT}$ ( $\Delta \mathrm{CT}$ (calibrator) $-\Delta \mathrm{CT}$ (sample)) was then calculated for each sample and relative quantification was calculated as $2 \Delta \Delta \mathrm{CT}$. Initial exclusion criteria consisted of FAM $\mathrm{CT} \geq 40$ and $\mathrm{VIC} \mathrm{CT} \geq 23$.

\section{Statistical analysis}

Data are presented as mean \pm SEM. Comparisons between days one and three of exercise on delta glycogen were performed with student's $t$ test. The effect of time and day was determined using a $2 \times 2$ (day $\times$ time) repeated measures ANOVA (SPSS version 14.0, Chicago, IL) for muscle parameters. Correlations were run using a Pearson Product Moment correlation (SPSS version 14.0, Chicago, IL). Statistical significance was set at $P \leq 0.05$.

\section{Results}

Subject characteristics are presented in Table 1. Although considered trained (Jeukendrup et al. 2000), these subjects were not elite. The subjects averaged $1.5 \pm 0.2 \mathrm{~h}$ during their regular training bouts, therefore the $9 \mathrm{~h}$ over the three consecutive days doubled their normal training load. Diet analysis demonstrated that macronutrient intake was $56.6 \pm 2.5 \%$ carbohydrate, $16.2 \pm 0.8 \%$ protein, and $27.2 \pm 1.8 \%$ fat.

All subjects successfully completed the exercise trials without significant weight loss. Average weight loss over the 3 days was $0.66 \pm 0.12 \mathrm{~kg}$. Prescribed intensity (57\% of watts max $_{\text {man }}$ ) was maintained by 34 of 40 subjects on day one, 38 of 40 on day two, and 38 of 40 on day three and averaged $179.4 \pm 3.0$ watts. The maximum wattage reduction in order to allow the subjects to finish the trial was 20 watts on day one and 10 watts on days two and three. Thus there was not a significant effect of time on power output

Table 1 Subject characteristics measured at baseline (mean \pm SEM)

\begin{tabular}{|c|c|}
\hline Variable & Cyclists $(N=40)$ \\
\hline Age (years) & $29.1 \pm 2.4$ \\
\hline Weight (kg) & $74.2 \pm 1.4$ \\
\hline Body fat (\%) & $11.5 \pm 0.6$ \\
\hline $\mathrm{VO}_{2 \max }\left(\mathrm{ml} \mathrm{kg}^{-1} \min ^{-1}\right)$ & $54.7 \pm 1.1$ \\
\hline Power $_{\text {max }}$ (watts) & $320 \pm 69$ \\
\hline Relative power (watts $\mathrm{kg}^{-1}$ ) & $4.33 \pm 0.37$ \\
\hline $\mathrm{HR}_{\max }$ (beats $\min ^{-1}$ ) & $190 \pm 2$ \\
\hline Training distance $\left(\mathrm{km} \mathrm{week}^{-1}\right)$ & $270 \pm 29$ \\
\hline
\end{tabular}

$\mathrm{VO}_{2}$ volume of oxygen consumption; $H R$ heart rate during the trials. However, there was a significant increase over the $3 \mathrm{~h}$ trials in oxygen consumption and RPE $(P<0.001$, data not shown). Heart rate (HR) increased during the $3 \mathrm{~h}$ trials $(P<0.001)$ but was not affected by day (data not shown). RER decreased over time $(P<0.001)$ though a day effect was not observed $(P>0.05$, data not shown).

Muscle glycogen concentration from pre to post on days one and three is shown in Fig. 1. There was a significant effect of pre- to post-exercise $(P<0.001)$ and day $(P=0.04)$ on muscle glycogen. PGC- $1 \alpha$ mRNA increased following exercise $(P<0.001)$ on both days but was not significantly different from day one to three (Fig. 2). Sirt-1 mRNA was increased post-exercise $(P=0.005)$ but was not different between day one and three (Fig. 3). Cytochrome $c$ mRNA (Fig. 4) increased as the result of exercise $(P=0.006)$ and also demonstrated a significant day effect $(P<0.001)$. Citrate synthase mRNA was significantly increased from pre- to post-exercise $(P=0.03)$ and was different from day one to three $(P=0.01)$ (Fig. 5). The mRNA endogenous control (18S ribosomal RNA) was not affected by acute exercise or time.

Significant correlations were found between the pre-post changes in PGC- $1 \alpha$ mRNA on day 1 and the changes in cytochrome $c$ mRNA on day $1(r=0.73, p<0.001)$ and sirt-1 mRNA on day $1(r=0.59, p<0.001)$. On day 3, changes in PGC- $1 \alpha$ mRNA also related to changes in cytochrome $c$ mRNA $(r=0.65, p<0.001)$, changes in citrate synthase mRNA $(r=0.71, p<0.001)$, and changes in sirt-1 mRNA $(r=0.62, p<0.001)$. Pre to post exercise changes in these markers on day 1 did not correlate to changes on day 3, indicating a specificity of these relationships. Pre, post and changes in glycogen on days 1 and 3 were not correlated with pre-post changes in any of the mRNA markers analyzed.

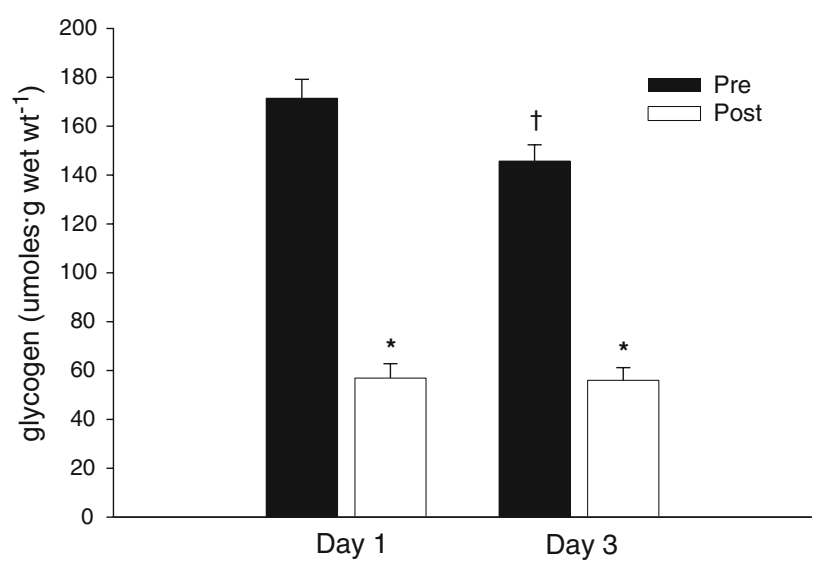

Fig. 1 Muscle glycogen concentration pre and post 3-h rides on days one and three. Data indicate mean \pm SEM. *Significant effect from pre- to post-exercise. ${ }^{\dagger}$ Significant day effect 


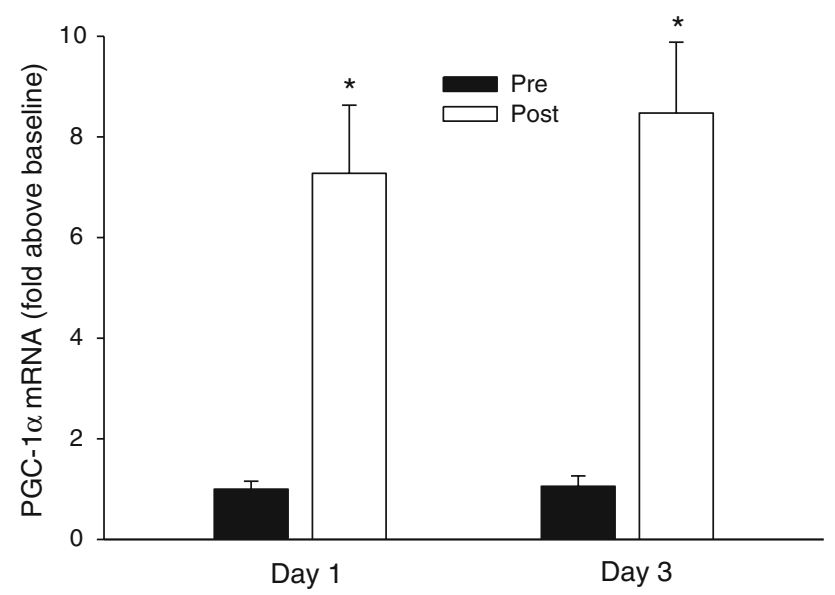

Fig. 2 Muscle PGC- $1 \alpha$ mRNA pre and post $3 \mathrm{~h}$ rides on days one and three. Data indicate mean \pm SEM. *Significant effect from pre- to post-exercise. ${ }^{\dagger}$ Significant day effect

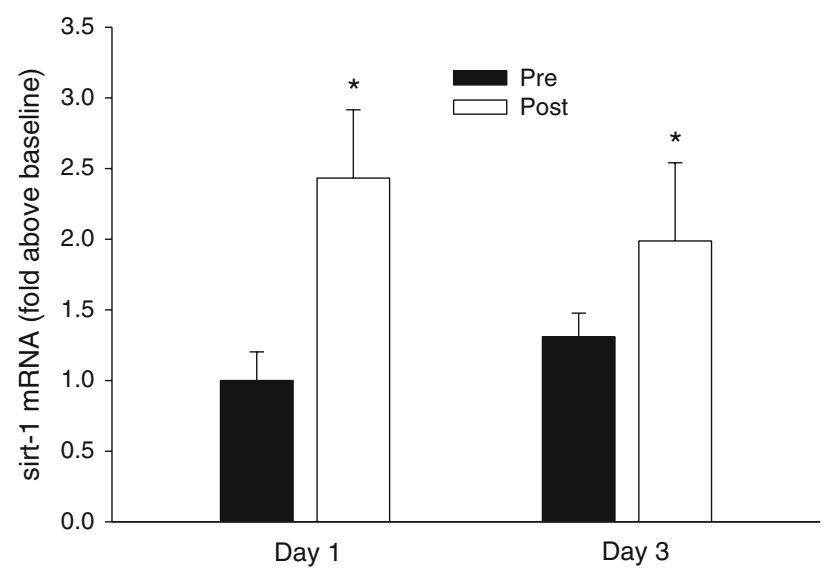

Fig. 3 Muscle sirt-1 mRNA pre and post 3-h rides on days one and three. Data indicate mean \pm SEM. *Significant effect from pre- to post-exercise. ${ }^{\dagger}$ Significant day effect

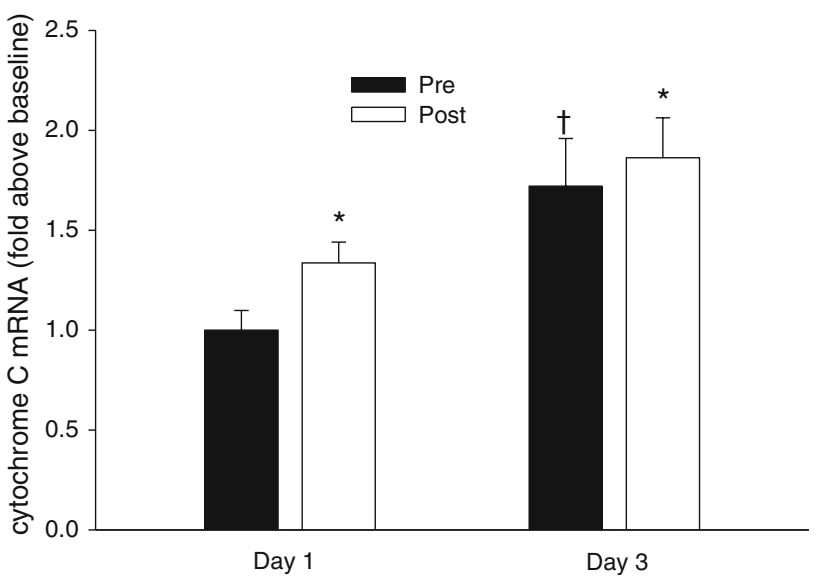

Fig. 4 Muscle cytochrome c mRNA pre and post 3-h rides on days one and three. Data indicate mean \pm SEM. *Significant effect from pre- to post-exercise. ${ }^{\dagger}$ Significant day effect

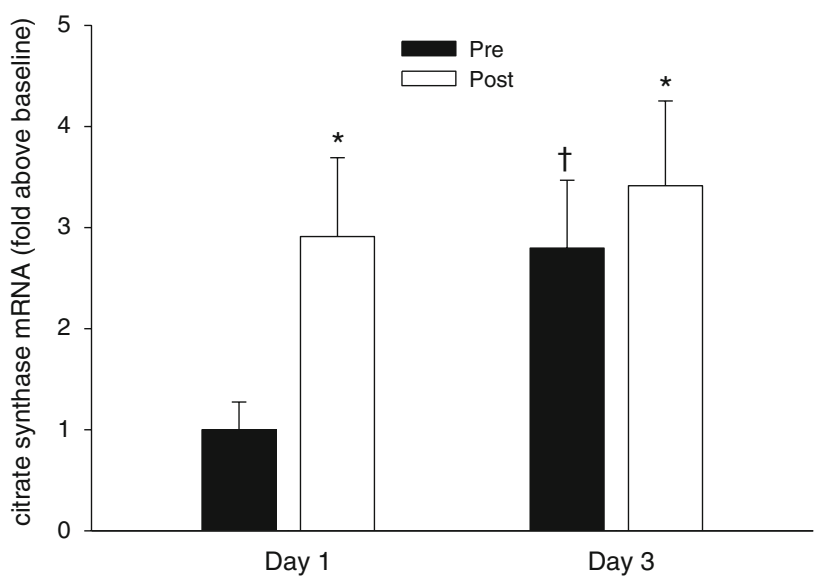

Fig. 5 Muscle citrate synthase mRNA pre and post 3-h rides on days one and three. Data indicate mean \pm SEM. *Significant effect from pre- to post-exercise. ${ }^{\dagger}$ Significant day effect

\section{Discussion}

Exercise increases expression of several genes involved in mitochondrial biogenesis and oxidative enzyme capacity (Civitarese et al. 2007; Hood et al. 2006; Wright et al. 2007). However, little is known about how these genes respond to several consecutive bouts of intensive exercise in humans. The primary purpose of this study was to examine the effects of $3 \mathrm{~h}$ of intensive cycling performed on three consecutive days on mRNA associated with mitochondrial biogenesis in trained cyclists. The primary result from this investigation is that cycling for three consecutive days resulted in both acute and chronic stimuli for mRNA associated with mitochondrial biogenesis. Three days of cycling caused acute increases in mRNA of the upstream elements PGC- $1 \alpha$ and Sirt- 1 and chronic increases in the downstream targets of cytochrome $c$ and citrate synthase. These data contribute to the understanding of the exercise stimulus regulating mRNA involved in mitochondrial biogenesis. To our knowledge this is the first study to demonstrate an upregulation of the Sirt-1 gene following exercise in humans. Also three consecutive bouts of exercise generated cumulative increases in cytochrome $c$ and citrate synthase mRNA, whereas increases in PGC- $1 \alpha$ and Sirt-1 mRNA are specific to the acute exercise stimulus and appear to not be cumulative.

Mitochondrial biogenesis is stimulated by a number of factors. Following exercise, the shared upstream proteins appear to be AMPK, PGC- $1 \alpha$ and Sirt-1 (Canto et al. 2009; Freyssenet 2007; Hood 2001; Hood et al. 2006; Norrbom et al. 2004; Ojuka 2004; Pilegaard et al. 2003; Winder et al. 2006; Wright 2007). We have shown here a transient increase in PGC- $1 \alpha$ and Sirt- 1 mRNA as the result of three consecutive days of $3 \mathrm{~h}$ of cycling in trained cyclists. This 
is consistent with previous reports that PGC- $1 \alpha$ is increased following muscle contractions and whole body exercise (Akimoto et al. 2005; Baar et al. 2002; Goto et al. 2000; Miura et al. 2007; Norrbom et al. 2004; Pilegaard et al. 2003; Russell et al. 2003). Akimoto et al. (2005) reported a transient increase in PGC- $1 \alpha$ following voluntary wheel running in mice that returned to baseline $6 \mathrm{~h}$ post-exercise. Rat triceps muscle exhibited elevated PGC- $1 \alpha$ mRNA up to $18 \mathrm{~h}$ following swimming (Baar et al. 2002). In humans, PGC- $1 \alpha$ mRNA was elevated at 2 and $6 \mathrm{~h}$ following knee extensor or cycling exercise but had returned to baseline $24 \mathrm{~h}$ post-exercise (Mathai et al. 2008; Pilegaard et al. 2003). Together with the current data, PGC- $1 \alpha$ mRNA appears to be an acute and transient response. The mRNA of this protein does not appear to be affected by previous bouts of exercise, since the profiles from the first and third day appear identical in the current study. This is supported by research which reported no effect of multiple daily bouts of exercise on expression of the PGC- 1 family $(\alpha, \beta$, and PRC) following $3 \mathrm{~h}$ of knee extensor exercise (Mortensen et al. 2007). This group did not, however, report mRNA content of proteins downstream of these transcriptional coactivators. What remains to be determined is whether repeated elevations in PGC- $1 \alpha$ mRNA from frequent bouts of exercise amplifies, in a summative or exponential manner, the downstream signals for metabolic gene expression.

Our data indicate that downstream targets such as cytochrome $c$ and citrate synthase mRNA remain elevated during consecutive bouts of exercise. It has long been known that endurance exercise increases oxidative enzyme capacity such as cytochrome $c$ and citrate synthase activity (Holloszy 1967). Recent work by Wright et al. (2007) has advanced understanding of the cascade of events from mRNA upregulation to protein expression for mitochondrial biogenesis. They propose a sequence of events that involves two phases of mitochondrial adaptation. Exercise first stimulates p38 MAPK to phosphorylate existing cytosolic PGC- $1 \alpha$ protein which progresses into the nucleus of the muscle cell to upregulate mitochondrial proteins, including its own gene expression. The resulting increase in PGC- $1 \alpha$ mRNA then drives the second phase of adaptation by sustaining the stimuli for expression of mitochondrial proteins. Even though we do not have a measure of PGC- $1 \alpha$ protein, our data support this proposal in that we observed an acute and chronic elevation in cytochrome $c$ and citrate synthase mRNA. The acute increase may have been stimulated initially by endogenous PGC- $1 \alpha$ protein, whereas the chronic elevation may have been the result of the upregulation of PGC- $1 \alpha$ mRNA and subsequent protein expression from the first day of exercise.

Factors influencing Sirt-1 mRNA are less understood. This 'longevity gene' is thought to be an important factor in health and aging (Bordone et al. 2007; Bordone and Guarente 2005). Overexpression of this gene mimics many of the beneficial effects of calorie restriction (Bordone et al. 2007). We have shown here that Sirt-1 mRNA increased acutely following $3 \mathrm{~h}$ of cycling. Sirt-1 has been shown to regulate the activity of PGC- $1 \alpha$ by deacetylation (Nemoto et al. 2005), but no data to our knowledge have shown the Sirt-1 mRNA expression response to exercise in humans. Caloric restriction increases Sirt- 1 and PGC- $1 \alpha$ mRNA and mitochondrial function in humans (Civitarese et al. 2007). Logically, exercise would disrupt the myocyte NAD+/ NADH ratio, to which Sirt-1 is sensitive, to a greater extent compared to caloric restriction. Indeed, Sirt-1 mediated deacetylation of PGC- $1 \alpha$ is increased by AMPK activation in skeletal muscle following exercise in mice (Canto et al. 2009). Likewise, exercise attenuates the age related loss of Sirt-1 protein in the heart muscle of rats (Ferrara et al. 2008). More specifically, Suwa et al. (2008) showed that acute and chronic treadmill running resulted in increases in Sirt- 1 and PGC- $1 \alpha$ protein in the soleus of rats. They suggest that because it required high intensity training to increase Sirt-1, but not PGC-1 $\alpha$ protein in plantaris muscle, that Sirt-1 may be more important in the skeletal muscle adaptations to exercise. Our data, combined with previous reports of exercise stimulating the phosphorylation and deacetylation of PGC- $1 \alpha$ through p38 MAPK (Ikeda et al. 2008; Wright et al. 2007), suggest that a variety of stimuli are capable of increasing mitochondrial biogenesis and function. Whether Sirt-1 deacetylation, or p38 MAPK phosphorylation, or the combination of the two, has the greatest influence on the activity of PGC- $1 \alpha$ remains to be seen.

Increases in mRNA do not always lead to increases in protein as there are many points of regulation of protein expression following transcription. The amount of time necessary for mRNA to result in increased functional protein is unclear and may vary between genes. Since we sampled muscle immediately post-exercise and after the 3 days of exercise, this would unlikely allow enough time for protein expression to occur equally in both upstream and downstream elements. Baar et al. (2002) did show that swimming rats resulted in both PGC- $1 \alpha$ mRNA and protein elevation $18 \mathrm{~h}$ post-exercise. Mathai et al. (2008) provided a time course of PGC- $1 \alpha$ protein expression. They demonstrated that PGC- $1 \alpha$ mRNA was elevated immediately following cycling to exhaustion and at $2 \mathrm{~h}$ post exercise. PGC- $1 \alpha$ protein was increased post exercise and at 2 and $24 \mathrm{~h}$, and this protein expression was dependent on glycogen availability. They did not, however, measure any of the PGC- $1 \alpha$ targets involved in oxidative metabolism. It is consistent, however, with the premise that PGC- $1 \alpha$ may be at least partially regulated by Sirt-1, which is activated by AMPK (Canto et al. 2009). The time course from upstream elements such as PGC- $1 \alpha$ mRNA to mitochondrial oxidative protein expression is less clear. Wright et al. (2007) investigated this relationship and found that activation of endogenous PGC- $1 \alpha$ 
protein is capable of upregulation of cytochrome $c$ mRNA before increases in PGC- $1 \alpha$ protein content. Whether this is through phosphorylation by p38 MAPK or some allosteric regulation remains to be seen. It has been suggested that it may take days to weeks for the exercise stimulation of gene transcription to result in a complete upregulation in mitochondrial oxidative protein expression and assembly (Hood 2001). Further work is needed to elucidate the mechanism behind this cascade of events.

Several components of the design of this experiment may have amplified the mitochondrial marker response. Although the subjects were trained, the exercise in this experiment ( $3 \mathrm{~h} /$ day) represented a doubling of their normal training load ( $1.5 \mathrm{~h} /$ day). During the $3 \mathrm{~h}$ trials, subjects did not ingest exogenous carbohydrate. Because of this subjects often had trouble finishing the trials despite the moderate intensity. It has previously been shown that exogenous carbohydrate may blunt the upregulation of oxidative enzyme expression during aerobic exercise (Akerstrom et al. 2006; Civitarese et al. 2005; Cluberton et al. 2005). This may be a result of reduced PGC- $1 \alpha$ protein expression upon carbohydrate ingestion (Mathai et al. 2008). It remains unclear, however, whether this is due to attenuated glycogen depletion, or a reduction in 'metabolic stress'. Previous evidence supports that greater muscle glycogen depletion leads to greater enhancement in oxidative phosphorylation enzymes, mitochondrial biogenesis, and endurance performance (Cluberton et al. 2005; Hansen et al. 2005). AMPK activation is enhanced with greater amounts of glycogen depletion, and this may lead to amplification of its downstream targets including Sirt-1 and PGC- $1 \alpha$ (Canto et al. 2009; Steinberg et al. 2006). However, it is generally accepted that exogenous carbohydrate during continuous endurance exercise does not significantly spare muscle glycogen (Coyle et al. 1986), but leads to greater performance through other mechanisms (Febbraio et al. 2000). In the current study, we demonstrated strong relationships between changes in PGC- $1 \alpha$ and downstream oxidative enzyme transcription, but there was no relationship between pre, post or delta glycogen and changes in mitochondrial biogenesis mRNA markers. Muscle IL-6 as an inflammatory marker of metabolic stress has also been shown to be attenuated with exogenous carbohydrate intake during exercise (Pedersen et al. 2004). The precise relationship between glycogen depletion, AMPK activation, exogenous carbohydrate intake, and upregulation of inflammatory markers in the stimuli of mitochondrial biogenesis requires more investigation.

The current study did not include a measure of endurance performance. However, changes in oxidative enzyme activity such as cytochrome $c$ and citrate synthase are typically associated with greater aerobic capacity. Compelling evidence has shown that there may be greater stimuli for the development of oxidative capacity by training twice a day compared to once a day (Hansen et al. 2005). Thus the 'train low, race high' theory is that training on low muscle glycogen results in greater stimuli for enhancement of oxidative enzyme activity, mitochondrial biogenesis, and endurance performance (Hansen et al. 2005). But the association between enhanced oxidative enzyme activity and endurance performance may not be as tight as logic would allow. A recent investigation found elevated citrate synthase, cytochrome $c$ oxidase, and $\beta$-hydroxyacyl-CoA dehydrogenase activities following exercise done twice a day every other day compared to training every day in trained cyclists (Yeo et al. 2008). Despite this, they did not show an increase in cycling performance. Anecdotally, many of the subjects from the current study reported outstanding individual performances in the days and weeks following the 3 days of exhaustive continuous steady state exercise in the absence of exogenous carbohydrate intake. The explanations for why enhanced oxidative enzyme activities may or may not result in improved aerobic performance may have to do with timing of measurements, training status of subjects, or the selection of the performance trial.

These data show that exhaustive cycling performed on three consecutive days resulted in both acute and chronic stimuli for mRNA associated with mitochondrial biogenesis in already trained subjects. Three hours of exhaustive exercise for three consecutive days caused a transient elevation in PGC- $1 \alpha$ and Sirt- 1 mRNA and a cumulative increase in mRNA for the downstream genes of cytochrome $c$ and citrate synthase. This is the first study to illustrate an increase in Sirt-1 mRNA with acute and chronic exercise. This suggests that Sirt-1 is responsive to exercise stimuli and is involved in the adaptations to endurance training. These data contribute to the understanding of mRNA expression during both acute and successive bouts of prolonged exercise.

Acknowledgments The authors wish to thank the subjects for their investment in time and energy. We would like to thank the following ASU graduate students involved in the data collection for this investigation, including: Jessica Unick, John Troy Owens, Matt Hudson, Peter Hosick, Steven Pearce, Timothy McInnis, Heather LaSasso, Michael Rigby and Sean Schumm. This study was partially supported by a grant from the Defense Advanced Research Projects Agency (DARPA) and the Army Research Office (ARO), award number W911NF-06-0014.

Conflict of interest statement The authors did not have any conflict of interest in access to these data or associations with companies involved with products used in this research.

\section{References}

Akerstrom TC, Birk JB, Klein DK, Erikstrup C, Plomgaard P, Pedersen BK, Wojtaszewski J (2006) Oral glucose ingestion 
attenuates exercise-induced activation of $5^{\prime}$-AMP-activated protein kinase in human skeletal muscle. Biochem Biophys Res Commun 342:949-955

Akimoto T, Pohnert SC, Li P, Zhang M, Gumbs C, Rosenberg PB, Williams RS, Yan Z (2005) Exercise stimulates Pgc-1alpha transcription in skeletal muscle through activation of the p38 MAPK pathway. J Biol Chem 280:19587-19593

Baar K, Wende AR, Jones TE, Marison M, Nolte LA, Chen M, Kelly DP, Holloszy JO (2002) Adaptations of skeletal muscle to exercise: rapid increase in the transcriptional coactivator PGC-1. Faseb J 16:1879-1886

Bordone L, Guarente L (2005) Calorie restriction, SIRT1 and metabolism: understanding longevity. Nat Rev 6:298-305

Bordone L, Cohen D, Robinson A, Motta MC, van Veen E, Czopik A, Steele AD, Crowe H, Marmor S, Luo J, Gu W, Guarente L (2007) SIRT1 transgenic mice show phenotypes resembling calorie restriction. Aging Cell 6:759-767

Borg G (1982) Ratings of perceived exertion and heart rates during short-term cycle exercise and their use in a new cycling strength test. Int J Sports Med 3:153-158

Canto C, Gerhart-Hines Z, Feige JN, Lagouge M, Noriega L, Milne JC, Elliott PJ, Puigserver P, Auwerx J (2009) AMPK regulates energy expenditure by modulating NAD+ metabolism and SIRT1 activity. Nature 458:1056-1060

Civitarese AE, Hesselink MK, Russell AP, Ravussin E, Schrauwen P (2005) Glucose ingestion during exercise blunts exercise-induced gene expression of skeletal muscle fat oxidative genes. Am J Physiol Endocrinol Metab 289:E1023-E1029

Civitarese AE, Carling S, Heilbronn LK, Hulver MH, Ukropcova B, Deutsch WA, Smith SR, Ravussin E (2007) Calorie restriction increases muscle mitochondrial biogenesis in healthy humans. PLoS Med 4:e76

Cluberton LJ, McGee SL, Murphy RM, Hargreaves M (2005) Effect of carbohydrate ingestion on exercise-induced alterations in metabolic gene expression. J Appl Physiol 99:1359-1363

Coyle EF, Coggan AR, Hemmert MK, Ivy JL (1986) Muscle glycogen utilization during prolonged strenuous exercise when fed carbohydrate. J Appl Physiol 61:165-172

Evans WJ, Phinney SD, Young VR (1982) Suction applied to a muscle biopsy maximizes sample size. Med Sci Sports Exerc 14:101-102

Febbraio MA, Chiu A, Angus DJ, Arkinstall MJ, Hawley JA (2000) Effects of carbohydrate ingestion before and during exercise on glucose kinetics and performance. J Appl Physiol 89:2220-2226

Ferrara N, Rinaldi B, Corbi G, Conti V, Stiuso P, Boccuti S, Rengo G, Rossi F, Filippelli A (2008) Exercise training promotes SIRT1 activity in aged rats. Rejuvenation Res 11:139-150

Freyssenet D (2007) Energy sensing and regulation of gene expression in skeletal muscle. J Appl Physiol 102:529-540

Goto M, Terada S, Kato M, Katoh M, Yokozeki T, Tabata I, Shimokawa T (2000) cDNA Cloning and mRNA analysis of PGC-1 in epitrochlearis muscle in swimming-exercised rats. Biochem Biophys Res Commun 274:350-354

Hansen AK, Fischer CP, Plomgaard P, Andersen JL, Saltin B, Pedersen BK (2005) Skeletal muscle adaptation: training twice every second day vs. training once daily. J Appl Physiol 98:93-99

Holloszy JO (1967) Biochemical adaptations in muscle. Effects of exercise on mitochondrial oxygen uptake and respiratory enzyme activity in skeletal muscle. J Biol Chem 242:2278-2282

Hood DA (2001) Invited review: contractile activity-induced mitochondrial biogenesis in skeletal muscle. J Appl Physiol 90:1137-1157

Hood DA, Irrcher I, Ljubicic V, Joseph AM (2006) Coordination of metabolic plasticity in skeletal muscle. J Exp Biol 209:22652275

Ikeda SI, Kizaki T, Haga S, Ohno H, Takemasa T (2008) Acute exercise induces biphasic increase in respiratory mRNA in skeletal muscle. Biochem Biophys Res Commun 368:323-328
Jeukendrup AE, Craig NP, Hawley JA (2000) The bioenergetics of World Class Cycling. J Sci Med Sport 3:414-433

Livak KJ, Schmittgen TD (2001) Analysis of relative gene expression data using real-time quantitative PCR and the $2(\Delta \Delta \mathrm{C}(\mathrm{T}))$ method. Methods 25:402-408

Mathai AS, Bonen A, Benton CR, Robinson DL, Graham TE (2008) Rapid exercise-induced changes in PGC-1alpha mRNA and protein in human skeletal muscle. J Appl Physiol 105:1098-1105

Miura S, Kawanaka K, Kai Y, Tamura M, Goto M, Shiuchi T, Minokoshi Y, Ezaki O (2007) An increase in murine skeletal muscle peroxisome proliferator-activated receptor-gamma coactivator-1alpha (PGC- $1 \alpha)$ mRNA in response to exercise is mediated by beta-adrenergic receptor activation. Endocrinology 148:3441-3448

Mortensen OH, Plomgaard P, Fischer CP, Hansen AK, Pilegaard H, Pedersen BK (2007) PGC-1beta is downregulated by training in human skeletal muscle: no effect of training twice every second day vs. once daily on expression of the PGC-1 family. J Appl Physiol 103:1536-1542

Moseley L, Achten J, Martin JC, Jeukendrup AE (2004) No differences in cycling efficiency between world-class and recreational cyclists. Int J Sports Med 25:374-379

Nemoto S, Fergusson MM, Finkel T (2005) SIRT1 functionally interacts with the metabolic regulator and transcriptional coactivator PGC-1 $\alpha$. J Biol Chem 280:16456-16460

Nieman DC, Davis JM, Henson DA, Gross SJ, Dumke CL, Utter AC, Vinci DM, Carson JA, Brown A, McAnulty SR, McAnulty LS, Triplett NT (2005) Muscle cytokine mRNA changes after $2.5 \mathrm{~h}$ of cycling: influence of carbohydrate. Med Sci Sports Exerc $37: 1283-1290$

Norrbom J, Sundberg CJ, Ameln H, Kraus WE, Jansson E, Gustafsson T (2004) PGC-1alpha mRNA expression is influenced by metabolic perturbation in exercising human skeletal muscle. J Appl Physiol 96:189-194

Ojuka EO (2004) Role of calcium and AMP kinase in the regulation of mitochondrial biogenesis and GLUT4 levels in muscle. Proc Nutr Soc 63:275-278

Passonneau JV, Lauderdale VR (1974) A comparison of three methods of glycogen measurement in tissues. Anal Biochem 60:405-412

Pedersen BK, Steensberg A, Fischer C, Keller C, Keller P, Plomgaard P, Wolsk-Petersen E, Febbraio M (2004) The metabolic role of IL-6 produced during exercise: is IL- 6 an exercise factor? Proc Nutr Soc 63:263-267

Pilegaard H, Saltin B, Neufer PD (2003) Exercise induces transient transcriptional activation of the PGC-1alpha gene in human skeletal muscle. J Physiol 546:851-858

Russell AP, Feilchenfeldt J, Schreiber S, Praz M, Crettenand A, Gobelet C, Meier CA, Bell DR, Kralli A, Giacobino JP, Deriaz O (2003) Endurance training in humans leads to fiber type-specific increases in levels of peroxisome proliferator-activated receptorgamma coactivator-1 and peroxisome proliferator-activated receptor-alpha in skeletal muscle. Diabetes 52:2874-2881

Siri WE (1961) Body composition from fluid space and density. National Academy of Sciences, Washington, DC

Steinberg GR, Watt MJ, McGee SL, Chan S, Hargreaves M, Febbraio MA, Stapleton D, Kemp BE (2006) Reduced glycogen availability is associated with increased AMPK $\alpha 2$ activity, nuclear AMPK $\alpha 2$ protein abundance, and GLUT4 mRNA expression in contracting human skeletal muscle. Appl Physiol Nutr Metab $31: 302-312$

Suwa M, Nakano H, Radak Z, Kumagai S (2008) Endurance exercise increases the SIRT1 and peroxisome proliferator-activated receptor gamma coactivator-1alpha protein expressions in rat skeletal muscle. Metabolism 57:986-998

Timmons JA, Norrbom J, Scheele C, Thonberg H, Wahlestedt C, Tesch P (2006) Expression profiling following local muscle 
inactivity in humans provides new perspective on diabetes-related genes. Genomics 87:165-172

Winder WW, Taylor EB, Thomson DM (2006) Role of AMP-activated protein kinase in the molecular adaptation to endurance exercise. Med Sci Sports Exerc 38:1945-1949

Wright DC (2007) Mechanisms of calcium-induced mitochondrial biogenesis and GLUT4 synthesis. Appl Physiol Nutr Metab $32: 840-845$
Wright DC, Han DH, Garcia-Roves PM, Geiger PC, Jones TE, Holloszy JO (2007) Exercise-induced mitochondrial biogenesis begins before the increase in muscle PGC- $1 \alpha$ expression. J Biol Chem 282:194-199

Yeo WK, Paton CD, Garnham AP, Burke LM, Carey A, Hawley JA (2008) Skeletal muscle adaptation and performance responses to once a day versus twice every second day endurance training regimens. J Appl Physiol (90882.92008) 